\title{
Neuronal Circuitry Mechanisms Regulating Adult Mammalian Neurogenesis
}

\author{
Juan Song ${ }^{1,2}$, Reid H.J. Olsen ${ }^{1}$, Jiaqi Sun ${ }^{3,4}$, Guo-li Ming ${ }^{3,5,6,7}$, and Hongjun Song ${ }^{3,5,6,7}$ \\ ${ }^{1}$ Department of Pharmacology and Pharmacology Training Program, School of Medicine, University of \\ North Carolina, Chapel Hill, North Carolina 27599 \\ ${ }^{2}$ Neuroscience Center and Neurobiology Curriculum, University of North Carolina, Chapel Hill, \\ North Carolina 27599 \\ ${ }^{3}$ Institute for Cell Engineering, Johns Hopkins University School of Medicine, Baltimore, Maryland 21205 \\ ${ }^{4}$ School of Life Sciences, Tsinghua University, Beijing 100084, China \\ ${ }^{5}$ Department of Neurology, Johns Hopkins University School of Medicine, Baltimore, Maryland 21205 \\ ${ }^{6}$ The Solomon H. Snyder Department of Neuroscience, Johns Hopkins University School of Medicine, \\ Baltimore, Maryland 21205 \\ ${ }^{7}$ Adrienne Helis Malvin Medical Research Foundation, New Orleans, Louisiana 70130-2685 \\ Correspondence: juansong@email.unc.edu
}

\begin{abstract}
The adult mammalian brain is a dynamic structure, capable of remodeling in response to various physiological and pathological stimuli. One dramatic example of brain plasticity is the birth and subsequent integration of newborn neurons into the existing circuitry. This process, termed adult neurogenesis, recapitulates neural developmental events in two specialized adult brain regions: the lateral ventricles of the forebrain. Recent studies have begun to delineate how the existing neuronal circuits influence the dynamic process of adult neurogenesis, from activation of quiescent neural stem cells (NSCs) to the integration and survival of newborn neurons. Here, we review recent progress toward understanding the circuitbased regulation of adult neurogenesis in the hippocampus and olfactory bulb.
\end{abstract}

$\mathrm{N}^{\mathrm{e}}$ eurogenesis occurs throughout life in discrete regions of the mammalian brain and substantial evidence supports critical roles of adult-born neurons for specific brain functions, such as learning, memory, and olfactory processing (Kempermann and Gage 1999; Temple and Alvarez-Buylla 1999; Lledo et al. 2006; Zhao et al. 2008; Sahay et al. 2011). Under normal physiological conditions, significant levels of adult neurogenesis are limited to two brain re-

gions in mammals: the olfactory bulb (OB), in which newborn neurons migrate from the subventricular zone (SVZ) of the lateral ventricles, and the dentate granule cell (GC) layer of the hippocampus, in which newborn neurons are generated locally within the subgranular zone (SGZ) (Ninkovic and Gotz 2007; Duan et al. 2008). Significant progress has been made in understanding major steps underlying adult neurogenesis (Kempermann et al. 2004; Ming

Editors: Fred H. Gage, Gerd Kempermann, and Hongjun Song

Additional Perspectives on Neurogenesis available at www.cshperspectives.org

Copyright (C) 2016 Cold Spring Harbor Laboratory Press; all rights reserved

Advanced Online Article. Cite this article as Cold Spring Harb Perspect Biol doi: 10.1101/cshperspect.a018937 
J. Song et al.

and Song 2011). New neurons in these regions originate from a residential population of adult neural precursor cells (Gage 2000; AlvarezBuylla and Lim 2004; Ma et al. 2009a). Neurons born in the adult SVZ migrate over a great distance through the rostral migratory stream (RMS) and become mostly granule interneurons and periglomerular interneurons in the $\mathrm{OB}$, whereas neurons born in the adult SGZ migrate into the GC layer of the dentate gyrus (DG) and become glutamatergic dentate GCs in the hippocampus.

Active adult neurogenesis occurs in a highly complex local environment, referred to as the neurogenic niche, which supports neural precursor cells and their development (Zhao et al. 2008; Kriegstein and Alvarez-Buylla 2009; Ming and Song 2011). Neuronal activity and experience, presumably acting on the local niche, regulate each step of the adult neurogenesis progress, from neural progenitor proliferation to new neuron maturation, synaptic integration, and survival (Zhao et al. 2008; Ming and Song 2011; Song et al. 2012b). Niche constituents that support adult SVZ or SGZ neurogenesis include endothelial cells, ependymal cells, astrocytes, microglia, and mature neurons (Ma et al. 2005; Miller and Gauthier-Fisher 2009; Siegenthaler and Pleasure 2010; Goldman and Chen 2011; Ihrie and Alvarez-Buylla 2011). In contrast to embryonic neurogenesis, one hallmark of adult neurogenesis is its dynamic regulation by neuronal activity at specific stages (Lledo et al. 2006; Zhao et al. 2008). For example, exposure to an enriched environment promotes adult hippocampal neurogenesis by increasing new neuron survival (Kempermann et al. 1997). The local circuitry mechanisms that mediate experience and activity-dependent regulation of adult neurogenesis remain elusive, largely because of a lack of direct evidence linking neuronal activity from specific niche components to the regulation of distinct stages of adult neurogenesis. There is a large body of literature reporting critical roles of neurotransmitter signaling, mostly via systemic manipulation, in regulating neurogenesis at various stages (Jang et al. 2008; Masiulis et al. 2011; Young et al. 2011). For example, $\gamma$-aminobutyric acid
(GABA) depolarizes neural progenitors and postmitotic immature neurons in the adult DG and promotes their maturation, differentiation, synaptic integration, and survival (Tozuka et al. 2005; Ge et al. 2006; Jagasia et al. 2009; Li et al. 2009a; Sun et al. 2009; Duveau et al. 2011). However, the majority of early studies did not differentiate between a direct regulation by neurotransmitters on adult precursor cells and indirect effects by less proximal circuit activity on the neurogenic niche. Moreover, the source of this activity-driven neurotransmission in the niche has been ambiguous. The organization of neuronal circuitry that regulates neurogenesis, the presence of synaptic inputs from other brain regions, and the expression of receptor populations within the SVZ and SGZ have not been extensively examined. One major advance in recent years is the identification of functional inputs onto newborn neurons and their synaptic partners during adult neurogenesis and illustration of the functional impact of existing neural circuits on the neurogenesis process. Here, we review recent progress to identify local circuit activity and long-distance projections that regulate adult neurogenesis at various developmental stages in the adult mammalian SGZ/hippocampus and SVZ/OB. Our goal is to provide an updated view of the current status of this line of research, and discuss complex interactions between circuitries from various brain regions, and how they impact adult neurogenesis regulation and function.

\section{CIRCUITRY REGULATION OF ADULT HIPPOCAMPAL NEUROGENESIS}

\section{Adult Hippocampal Circuitry and Neurogenesis}

The hippocampal neural network is highly dynamic, with the capacity to modify its connectivity by changing the number and strength of synaptic contacts in an activity-dependent manner. Hippocampal principal neurons are located in three primary subregions: GCs in the DG, and pyramidal neurons in CA1 and CA3. The principal neurons are synaptically connected to form the "trisynaptic circuit" 
(Fig. 1A), representing the canonical signaling network of the hippocampus. Within this circuit, information flows first through the entorhinal cortex (EC), the afferent input to the DG through the medial and lateral perforant pathways (MPPs and LPPs), then to CA3 pyramidal cells via mossy fibers (axons of DG GCs), then to CA1 pyramidal cells via Schaffer collateral projections (axons of CA3 neurons), and finally to the subiculum and back to the EC (Claiborne et al. 1986; Kohler 1986). This primary hippocampal projection forms a closed loop wherein sensory information from specific cortical areas converges onto the $\mathrm{EC}$, is processed through the hippocampal circuitry, and returns to the cortical region of origin (Li et al. 2009b). Besides principal excitatory neurons that form the trisynaptic circuit, another major component in the hippocampus is the diverse GABA-releasing interneurons that govern the generation of field potential oscillations characteristic of the DG. Furthermore, adult hippocampal circuitry shows significant regulation by multiple modulatory neurotransmitters, such as acetylcholine (ACh) from septal nucleus and diagonal band of Broca, serotonin (5-HT) from dorsal (DRN) and median raphe nucleus (MRN), and dopamine (DA) from ventral tegmental area (VTA) (Fig. 1A,B).

Among hippocampal principal cells, only dentate GCs are continuously generated throughout adulthood in the DG. Self-renewing and multipotent neural stem cells (NSCs) residing in the SGZ, a narrow band of tissue lying between the GC layer and the hilus, give rise to both neurons and astrocytes, but not oligodendrocytes (Bonaguidi et al. 2011). The development of newborn neurons in the adult hippocampus can be divided into five distinct phases: (1) stem-cell maintenance, activation, and fate specification; (2) proliferation of intermediate neural progenitors and neuroblasts; (3) migration and initial pruning of newborn GCs; (4) maturation and functional integration of newborn neurons; and (5) late-phase maturation and maintenance of adult-born neurons (Fig. 1C). It is estimated that the entire neurodevelopmental process takes $\sim 7$ to $8 \mathrm{wk}$ in the young adult mouse brain, although this pace is affected by a number of environmental and pathological conditions (Zhao et al. 2006; Song et al. 2012a). Because of the dynamic circuit regulation of the adult neurogenic niche by a diverse set of neuromodulatory networks, dissecting the consequences of functional inputs in this multistep process is highly complicated (Kempermann et al. 2004; Ma et al. 2009c). In this section, we focus on the regulation of discrete stages of adult hippocampal neurogenesis by local circuitry and long-distance projections.

\section{Local Circuitry Regulation of Adult} Hippocampal Neurogenesis

\section{Local GABAergic Interneurons}

In addition to excitatory principal cells, such as dentate granule and EC pyramidal cells, hippocampal microcircuits recruit different types of GABAergic interneurons, which exert inhibitory control at the soma, proximal dendrites, distal dendrites, and the axonal initial segment of the principal cells (Freund and Buzsaki 1996; Houser 2007). The hippocampal interneurons are remarkably diverse in their location, morphology, targets, and expression of proteins, such as calcium-binding proteins (Freund and Buzsaki 1996; Maccaferri and Lacaille 2003). A number of interneurons with their axons in close proximity to the SGZ neurogenic niche can potentially exert functional impact on adult neurogenesis. These interneurons include molecular layer perforant path interneurons (MOPP), hilar commissural-associational pathway-related interneurons (HICAP), hilar perforant pathassociated interneurons (HIPP), stratum lacunosum-moleculare (L-M) interneurons, and basket cells (BCs) (Fig. 1B,C) (Han et al. 1993; Freund and Buzsaki 1996; Houser 2007).

Studies have just begun to characterize the interaction between local interneurons and adult precursors and their progeny, ranging from radial glia-like NSCs, proliferating intermediate neural progenitors and neuroblasts, and postmitotic immature neurons to mature neurons. Previously, manipulations were mostly performed in a cell-autonomous fashion through the "single-cell knockdown" approach 
J. Song et al.

A

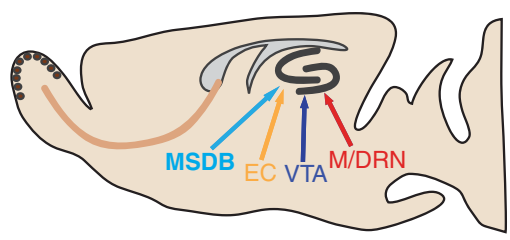

$\mathrm{ML}$

GCL

Hilus

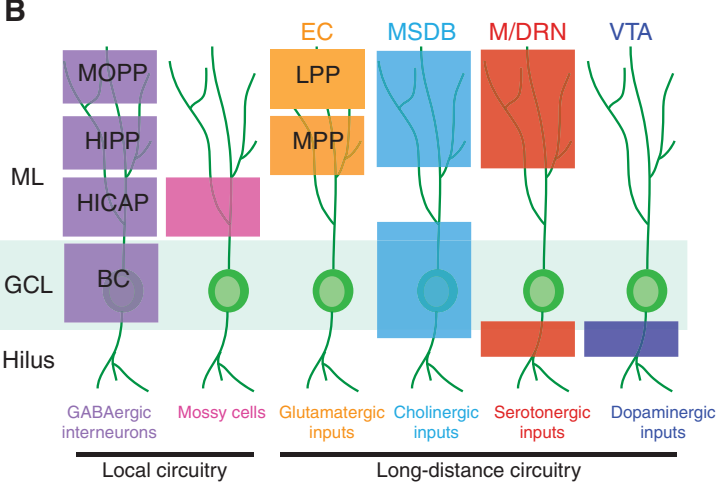

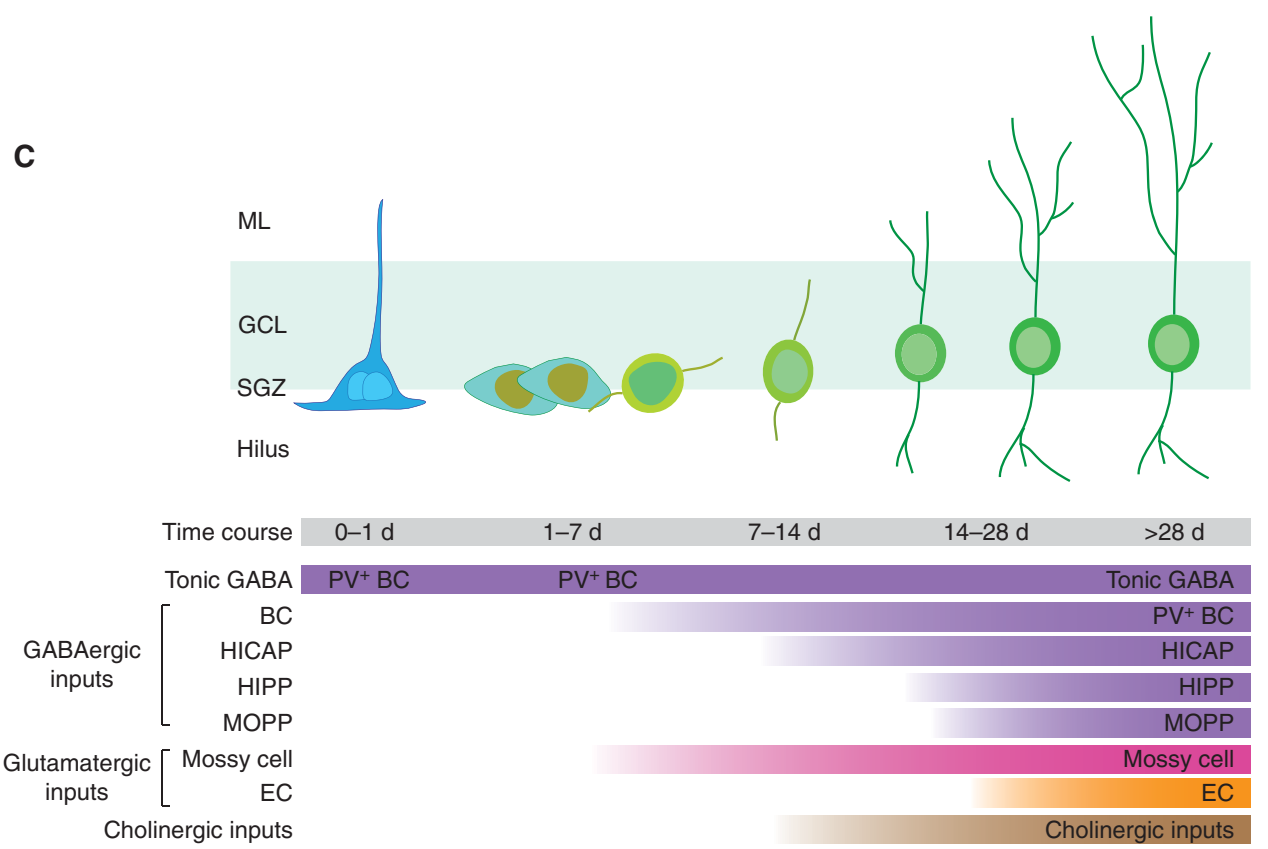

Figure 1. Circuitry regulation of adult neurogenesis in the dentate gyrus (DG). (A) A sagittal section view of an adult rodent brain highlighting the DG that shows active adult neurogenesis and the potential axonal projections into this region. (B) Local and long-distance axonal projections inputs to the DG. Color boxes indicate the laminar distribution of axon terminals of these inputs. ML, Molecular layer; GCL, granule cell layer; MOPP, molecular layer perforant path interneurons; HIPP, hilar perforant path-associated interneurons; HICAP, hilar commissural-associational pathway-related interneurons; BCs, basket cells; LPP, lateral perforant pathway; MPP, medial perforant pathway. $(C)$ Integration of newborn neurons in the DG during adult hippocampal neurogenesis. Shown is the summary of various inputs that appear at distinct stages of adult neurogenesis. MSDB, Medial septum and diagonal band of Broca; EC, entorhinal cortex; M/DRN, median and dorsal raphe nucleus; VTA, ventral tegmental area.

that uses a retrovirus expressing a short-hairpin RNA (shRNA) to infect proliferating neural progenitors, sometimes in combination with pharmacological manipulations. Moreover, because of the inability to use traditional electrodes to stimulate specific neuronal popula- tions in these experiments, precise analyses of circuit function and dynamics were not feasible. With recent technical advancements in circuitry manipulation via optogenetics, chemogenetics, DREADDs (designer receptors exclusively activated by designer drugs), and cross-synaptic 
tracing technology, the field is in a unique position to address fundamental questions underlying activity-dependent regulation of adult neurogenesis.

Using rabies virus-mediated retrograde tracing in combination with retroviral approach to label and birthdate newborn GCs, recent studies showed that adult-generated neurons receive local connections from multiple types of GABAergic interneurons, including parvalbumin-positive $\left(\mathrm{PV}^{+}\right) \mathrm{BCs}$, somatostatin-positive $\left(\mathrm{SST}^{+}\right)$HIPP cells, HICAP cells, and MOPP cells, such as neurogliaform cells/Ivy cells (Fig. 1C) (Vivar et al. 2012; Deshpande et al. 2013). The rabies virus-based transsynaptic tracing tool used in these studies is very informative in terms of defining both the organization of monosynaptic connections and how individual connections are integrated into polysynaptic networks. However, to identify the circuitbased regulation of early stages of adult neurogenesis (e.g., the NSC stage and early neural progenitor/neuroblast stages), the cross-synaptic tracing approach is not feasible, as no or very few immature synapses are present at those stages of development. Therefore, electrophysiological characterization is necessary to define the nature of functional inputs during initial phases of adult neurogenesis. A recent study using paired recording in acute slices showed that interneurons of the neurogliaform cell family provide a source of GABA for immature neurons labeled with proopiomelanocortin (POMC)-enhanced green fluorescent protein (EGFP) that are $\sim 11$ to $12 \mathrm{~d}$ after birth (Overstreet et al. 2004) in the adult mouse DG (Markwardt et al. 2011).

Despite recent progress in identifying afferent inputs to immature neurons, the evidence for local interneuron regulation of NSCs and precursor cells is still limited, largely because of the distinct properties of those cell populations, which prevent effective functional characterization. Furthermore, in vivo functional studies of those local interneurons in regulation of adult neurogenesis are still lacking. Using the combination of optogenetics and lineage tracing to target the quiescent radial glia-like NSCs, we have identified $\mathrm{PV}^{+}$interneurons as a cellular niche component that signals to quiescent
NSCs through $\gamma_{2}$-containing $\gamma$-aminobutyric acid type $A$ receptors $\left(\mathrm{GABA}_{\mathrm{A}} \mathrm{Rs}\right)$ in an activity-dependent fashion in the adult mouse DG. Moreover, optogenetic control of dentate $\mathrm{PV}^{+}$ neuron activity, but not $\mathrm{SST}^{+}$or vasoactive intestinal polypeptide $\left(\mathrm{VIP}^{+}\right)$interneurons, dictates the radial glia-like neural-stem-cell decision between quiescence and activation (Song et al. 2012b). In contrast to the direct synaptic inputs onto immature neurons in POMC-EGFP mice (Markwardt et al. 2009), no apparent functional GABAergic synaptic responses were detected when radial glia-like NSCs were recorded in this and previous studies (Wang et al. 2005), suggesting that GABA spillover from activated $\mathrm{PV}^{+}$interneuron-mature GC synapses indirectly regulates nearby radial stem cells. More recently, we showed that $\mathrm{PV}^{+}$interneurons make direct synaptic contacts with proliferating neuroblasts and regulate their survival and development in the adult DG (Song et al. 2012b, 2013). Together, these results reveal a striking diametric regulation of two early critical steps of adult neurogenesis via $\mathrm{PV}^{+}$neuron activity. In the DG with heightened activity, activation of $\mathrm{PV}^{+}$neurons inhibits quiescent neural-stem-cell activation while promoting the survival of proliferating neuronal progenitors already born. Conversely, when the activity in the $\mathrm{DG}$ is low, decreased $\mathrm{PV}^{+}$neuron activation promotes expansion of the quiescent neuralstem-cell pool via symmetric cell division and simultaneously suppresses the survival of proliferating neuronal progenitors. Therefore, these studies provide a point of entry for understanding how circuit dynamics impacts different phases of adult neurogenesis. Future studies with detailed characterization of various synaptic inputs onto adult-born neurons at different developmental stages will provide insights into spatial and temporal organization of various local circuitry niche components in relation to sequential stages of adult neurogenesis.

\section{Local Glutamatergic Neurons, Including Mossy Cells and Mature GCs}

Mossy cells are enriched in the hilar region of the hippocampal formation, and thought to be 
J. Song et al.

the principal cells of the hilus, copopulating along with hilar interneurons (Buckmaster and Jongen-Relo 1999). Mossy cells project widely through the septotemporal axis of the hippocampus, with potentially highly complex local networks because of the contralateral projections from those cells (Buckmaster et al. 1996). Using rabies virus-mediated retrograde-tracing, recent studies showed that newborn GCs receive afferent inputs from mossy cells starting from 5 to $10 \mathrm{~d}$ after their birth (Vivar et al. 2012; Deshpande et al. 2013). Furthermore, electrophysiological recording of newborn neurons at various cell stages on stimulation of contralateral hilar mossy cells supports the early mossy cell innervation of newborn neurons before $14 \mathrm{~d}$ of cell age (Kumamoto et al. 2012). The finding that mossy cells form synapses onto new neurons at this early stage is surprising as it has been previously thought that excitatory glutamatergic input to new neurons occurs initially by EC projections through the perforant path and that such excitatory synapse formation takes place at a much later stage (Schmidt-Hieber et al. 2004; $\mathrm{Ge}$ et al. 2006). However, the functional role of mossy cells in regulation of adult neurogenesis is still unknown. Previous studies have shown that glutamatergic signaling through $N$-methyl-Daspartate receptors (NMDARs) is critical for competitive survival and integration of newborn neurons $\sim 2 \mathrm{wk}$ after they are born (Tashiro et al. 2006). Therefore, it is conceivable that innervation of new neurons from both contralateral mossy cells and EC represent the major glutamatergic inputs critical for newborn neuron survival.

One surprising finding from the retrograde tracing study is the possibility of massive but transient glutamatergic inputs from mature GCs to newborn GCs at immature stages (Vivar et al. 2012). Such intragranular connections have been previously observed after denervation of EC inputs to the DG, seizures, and brain injuries (Buckmaster et al. 2002; Marques-Mari et al. 2007; Murphy and Danzer 2011). However, such intragranular connections were only reported as a minority of the total connections by another study using a similar retrograde tracing approach (Deshpande et al. 2013). The discrepancy may lie in the use of different mouse lines and viral vectors between these studies. Furthermore, it cannot be ruled out that the observed mature newborn GC connections were a consequence of pseudo transduction (Deshpande et al. 2013). Therefore, further studies will be required to confirm the connection from a functional aspect using electrophysiology.

\section{Other Local Neurons}

In addition to the major DG cellular niche components discussed above, there is a small population of cholinergic interneurons in the DG. How these cholinergic interneurons might influence the process of adult neurogenesis remains largely unknown, because the major cholinergic input into the hippocampus is believed to come from the basal forebrain (Bartus et al. 1982; Frotscher et al. 2000).

\section{Long-Distance Circuitry Regulation of Adult Hippocampal Neurogenesis}

\section{EC Projection}

The EC provides the major excitatory input to the dentate GCs through the MPP and LPP, coursing through the medial and outer molecular layer (Witter 2007). Glutamate signaling has long been implicated in regulating adult hippocampal neurogenesis at multiple stages (reviewed in $\mathrm{Ge}$ et al. 2008). On stimulation of the EC-perforant path, patch-clamp recording analyses suggest that robust glutamatergic synaptic development between newborn dentate GCs and EC projections occurs 14 to $21 \mathrm{~d}$ of cell age (Ge et al. 2006). Similar findings were described in a cross-synaptic tracing study (Vivar et al. 2012). Because inputs from EC to newborn neurons only start to appear when newborn neurons reach $3 \mathrm{wk}$ of cell age and gradually mature after $4 \mathrm{wk}$ of cell age (Vivar et al. 2012), the direct contribution of EC inputs to adult neurogenesis regulation is more likely to be at the neuronal maturation stages. For instance, direct manipulation of glutamatergic synaptic inputs by stimulating perforant path 
has identified a critical period during which newborn neurons show enhanced long-term potentiation (LTP) (Schmidt-Hieber et al. 2004; Ge et al. 2007). Within 4-6 wk after they are born, new neurons show both a lower induction threshold and increased amplitude of LTP in response to a physiological pattern of stimulation. However, there could be indirect regulation through a non-cell-autonomous mechanism by modulating existing neuronal circuits. For instance, induction of LTP at the MPP-GC synapses promotes the proliferation of adult neural progenitors and survival of newborn neurons in an NMDAR-dependent fashion (Bruel-Jungerman et al. 2006; Chun et al. 2006). In addition, Gadd45b, via active DNA demethylation, promotes brain-derived neurotrophic factor (BDNF) and fibroblast growth factor (FGF)-1 expression in mature dentate GCs in response to neuronal activation, and deletion of Gadd45b reduces activity-induced proliferation of neural precursors and dendritic growth of newborn neurons in the adult hippocampus (Ma et al. 2009b). sFRP3, a naturally secreted Wnt inhibitor expressed by local mature dentate GCs, serves as an inhibitory niche factor to suppress multiple phases of adult neurogenesis, including quiescent neural-stem-cell activation, maturation, and dendritic growth of newborn neurons (Jang et al. 2013). In these cases, existing circuitry modulates properties of mature dentate GCs, which in turn affects adult neurogenesis at distinct stages via growth factors and morphogen signaling. Despite the recent progress in identifying glutamatergic signaling to the newborn neurons, it remains to be determined whether quiescent NSCs and intermediate neural progenitors possess functional glutamatergic inputs and, if so, what receptor subtypes may be involved and whether the effect is through synaptic or tonic signaling.

\section{Basal Forebrain GABAergic and Cholinergic Projections}

The DG receives cholinergic and GABAergic inputs from the septum, including the medial septum and diagonal band of Broca (MSDB), via the fimbria-fornix pathway (Fig. 1A,B)
Neuronal Circuitry and Mammalian Neurogenesis

(Amaral et al. 2007). Interestingly, the cholinergic and GABAergic components target different cell types. Fibers of the septal GABAergic projections terminate preferentially on other GABAergic interneurons, such as the DG BCs, in which they form inhibitory contacts. In contrast, the cholinergic septal projection to the DG terminates mainly on GCs, and makes excitatory contacts on dendritic spines (Lubke et al. 1997). This unique anatomical feature of septal projections from two distinct populations of neurons may provide a differentially regulated influence on adult neurogenesis at distinct stages in an activity-dependent fashion. Indeed, the hippocampal $\theta$ rhythm is regulated by both cholinergic and GABAergic systems of the septal nuclei. Therefore, it is possible that adult neurogenesis is directly regulated through distal cholinergic or GABAergic neurons, or indirectly regulated through the interaction between distal cholinergic or GABAergic neurons and local GABAergic interneurons.

To date, little is known about the role of septal GABAergic projects on adult neurogenesis, largely because of the confound of pharmacological manipulation of GABA signaling, which has global and local consequences, through GABAergic interneurons and projection GABAergic neurons. Accumulating evidence, although not through specific manipulation of the cholinergic-hippocampal circuit, suggests that cholinergic signaling is involved in the regulation of adult hippocampal neurogenesis (Fig. 1C). For example, selective lesion of the medial septum system negatively affects the proliferation of neural precursor cells (Cooper-Kuhn et al. 2004; Van der Borght et al. 2005) and the administration of ACh esterase inhibitors promotes NSC/neuronal progenitor cell proliferation and leads to a rapid calcium rise in the NSCs (Kaneko et al. 2006; Itou et al. 2011). Newborn neurons in nicotinic receptor $\alpha_{7}$ knockout mice showed delayed dendritic development and functional maturation (Campbell et al. 2010). These studies indicate that neural precursors and their progeny are stimulated by cholinergic activation; however, direct evidence of how cholinergic activity regulates distinct stages of adult neurogenesis is still lacking. 
J. Song et al.

In addition, it remains unclear how various $\mathrm{ACh}$ receptor subtypes in neural precursor cells and their progeny work together to coordinate their responses to cholinergic signaling. Future studies utilizing targeted manipulations of components of this circuit will be required to elucidate the true nature of cholinergic signaling on neurogenic circuitry of the hippocampus.

\section{Brainstem Serotonergic and Dopaminergic Projections}

Serotonergic fibers projecting to DG are thought to originate from brain stem raphe nuclei (Fig. $1 \mathrm{~A}, \mathrm{~B})$. The DG receives dense serotonergic projections in the molecular layer and hilus, and especially in the SGZ, in which synapses are thought preferentially formed on interneurons (Halasy and Somogyi 1993; Djavadian 2004). The targeted interneurons from these studies were primarily DG BCs and neurons expressing calcium-binding protein calbindin, suggesting that the effect serotonin (5-HT) exerts on adult neurogenesis may be indirect. It remains unclear how serotonin modulates the activity of these local GABAergic interneurons to influence adult hippocampal neurogenesis.

Studies of raphe innervation of DG have been limited and conflicting (Moore and Halaris 1975; Vertes et al. 1999; Bjarkam et al. 2003), probably because of the diversity and complexity of differential expression of 5-HT receptors in the DG. The serotonin receptor families are extremely diverse (Barnes and Sharp 1999), and they act on 15 different receptor subtypes and almost all of these receptors are expressed in the DG (el Mestikawy et al. 1989; Tecott et al. 1993; Vilaro et al. 1996; Djavadian et al. 1999; Clemett et al. 2000; Kinsey et al. 2001). Depending on what subsets of the serotonergic receptors are activated, DG neurons may be either depolarized or hyperpolarized by 5-HT and therefore increase or decrease their excitability, respectively. The opposing effects from different subsets of 5-HT receptor activation may explain conflicting results in some studies. For example, selective 5-HT depletion was reported to have no effects on proliferation, survival, and differentiation of SGZ neuronal progenitors in the adult hippocampus (Jha et al. 2006). Despite various manipulations leading to inconsistent results, it has been shown that an increase in the level of serotonin via various means enhances the proliferation and differentiation of neural progenitor cells (NPCs) (Malberg et al. 2000), whereas depletion of 5-HT results in reduced NPC proliferation and differentiation (Radley and Jacobs 2002). Future studies targeting the serotonergic-hippocampal circuitry in combination with genetic manipulations will help to tease out the complicated mechanisms associated with serotonergic circuitry and relevant receptor subtypes.

In contrast to dense cholinergic and serotonergic projections from septal and raphe nuclei, the DG receives diffusely distributed dopaminergic projections that originate mainly from cells located in the VTA (Fig. 1A,B) (Gasbarri et al. 1997). These dopaminergic fibers terminate mainly in the hilus. Dopaminergic axons contact progenitor cells in the DG SGZ (Höglinger et al. 2004) and form inhibitory synapses with dendrites and soma of dentate GCs. It has been proposed that DA plays a role in regulating the proliferation of neural precursor cells in the SGZ, although conflicting results have been reported (Höglinger et al. 2004; Park and Enikolopov 2010). Despite emerging studies that enhance our understanding of the role of DA during adult neurogenesis, the circuitry studies targeting dopaminergic regulation of distinct stages of adult neurogenesis are still largely lacking. Recently, a study using patch-clamp recording suggested that DA exerts distinct modulatory effects on dentate GCs at different developmental stages through different receptor subtypes. DA modulates the strength of cortical inputs that newborn neurons receive from MPP through D1-like receptors, whereas D2-like receptors mediate the modulation of MPP synapses on mature adult-born neurons (Mu et al. 2011). Future studies that examine the regulatory effects of DA neurons on local GABAergic interneurons will be important, as the excitation/inhibition balance critical for adult-born neuron development is likely to be differentially regulated by the same type of neurons. 


\section{CIRCUIT REGULATION OF ADULT OB NEUROGENESIS}

\section{Adult Olfactory Circuitry and Neurogenesis}

Although neurogenic niches for hippocampal and $\mathrm{OB}$ neurogenesis show many similarities, there are important differences. For instance, the whole process of adult hippocampal neurogenesis is physically restricted in the DG, with axons of newborn neurons reaching the CA3 region, whereas the SVZ neurogenesis is physically segregated from the $\mathrm{OB}$, in which integration of new neurons occurs. In addition, the SGZ is enriched in terminal projections from diverse brain regions and subjected to dynamic circuit activity-dependent regulation via many different neurotransmitters. In contrast, the adult SVZ does not reside within such a dense neuronal network, and the projections to SVZ from other brain regions are not well established.

In the adult SVZ, proliferating radial glialike precursor cells give rise to transient amplifying cells, which in turn generate neuroblasts (Fig. 2C). Neuroblasts form a chain and migrate through the RMS toward the OB through a tube formed by astrocytes (Lois et al. 1996). After reaching the core of the $\mathrm{OB}$, immature neurons detach from the RMS and migrate radially toward glomeruli, in which they differentiate into different subtypes of interneurons (reviewed in Lledo et al. 2006). The physical separation between their birthplace and final destination establishes two distinct compartments for potentially different modes of extrinsic regulation. Highly specialized niche structures, such as the RMS, may function to segregate the earlier stages of neurogenesis from influences of olfactory circuit activity. After neuroblasts migrate through the RMS and reach the OB, in which olfactory information processing takes place, the newly generated neurons begin to migrate radially to their final positions and start to receive synaptic inputs. Thereafter, they are subject to activity-dependent survival processes and finally integrate into the preexisting circuitry. The circuitry organization and functional regulation of adult SVZ neurogenesis is not
Neuronal Circuitry and Mammalian Neurogenesis

well understood, partly because of many different types of interneurons located in different portions of the granule cell layer (GCL) and glomerular layer (GL). This fact complicates assigning a specific population of presynaptic neurons to its postsynaptic newborn neuron population. Nevertheless, significant progress has been made through the advent of recent tools, including transsynaptic tracing, optogenetics, pharmacogenetics based on DREADDs, immunoelectron microscopy, and electrophysiology (Bardy et al. 2010; Arenkiel et al. 2011; Katagiri et al. 2011; Ferguson and Neumaier 2012; Deshpande et al. 2013). Because of the physical distance between SVZ and the $\mathrm{OB}$, it is difficult to define the local and longdistance circuitries relative to adult-born cells at various spatiotemporal and developmental stages throughout the timeline of SVZ neurogenesis. Instead, we review the contribution of specific circuit inputs to the SVZ/OB region, and how they regulate adult olfactory neurogenesis (Fig. 2B).

\section{GABAergic-SVZ/OB Circuit}

The SVZ is located alongside the striatum, which comprises predominately GABAergic neurons. The striatal GABAergic neurons project to the SVZ (Moreno-Lopez et al. 2000), thus, may provide activity-dependent GABAergic influence over SVZ neurogenesis. In addition, vesicular GABA transporter expression has been reported in the SVZ, indicative of the presence of GABAergic inputs from the striatum (Platel et al. 2007). The function of GABAergic signaling on SVZ neurogenesis has been previously reviewed (Bordey 2006, 2007; Platel et al. 2008). Despite the fact that most functional studies thus far have been performed in vitro, recent evidence suggests that GABA exerts significant influence at several phases of SVZ/OB neurogenesis, including proliferation of the astrocyte-like stem cells and neuroblasts (Nguyen et al. 2003; Liu et al. 2005), as well as neuroblast migration and differentiation (Bolteus and Bordey 2004; Gascon et al. 2006). Interestingly, neuroblasts have been shown to synthesize and release GABA in a calcium-dependent but non- 
J. Song et al.

A

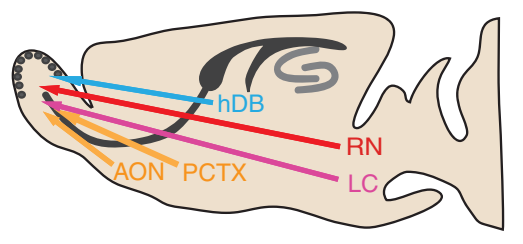

B

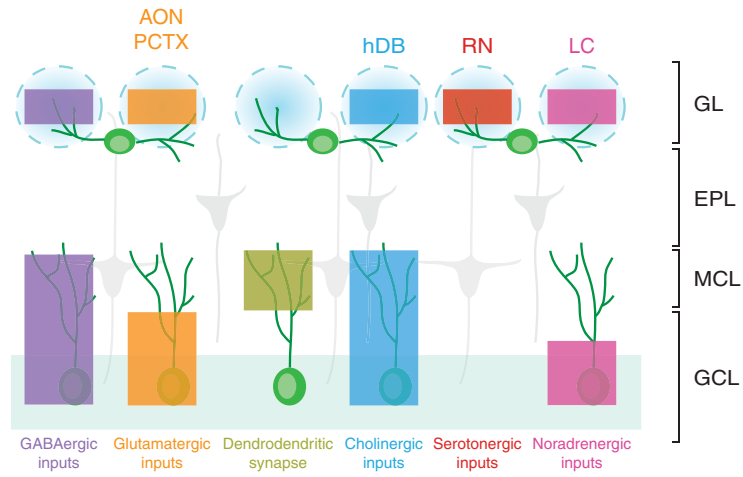

C

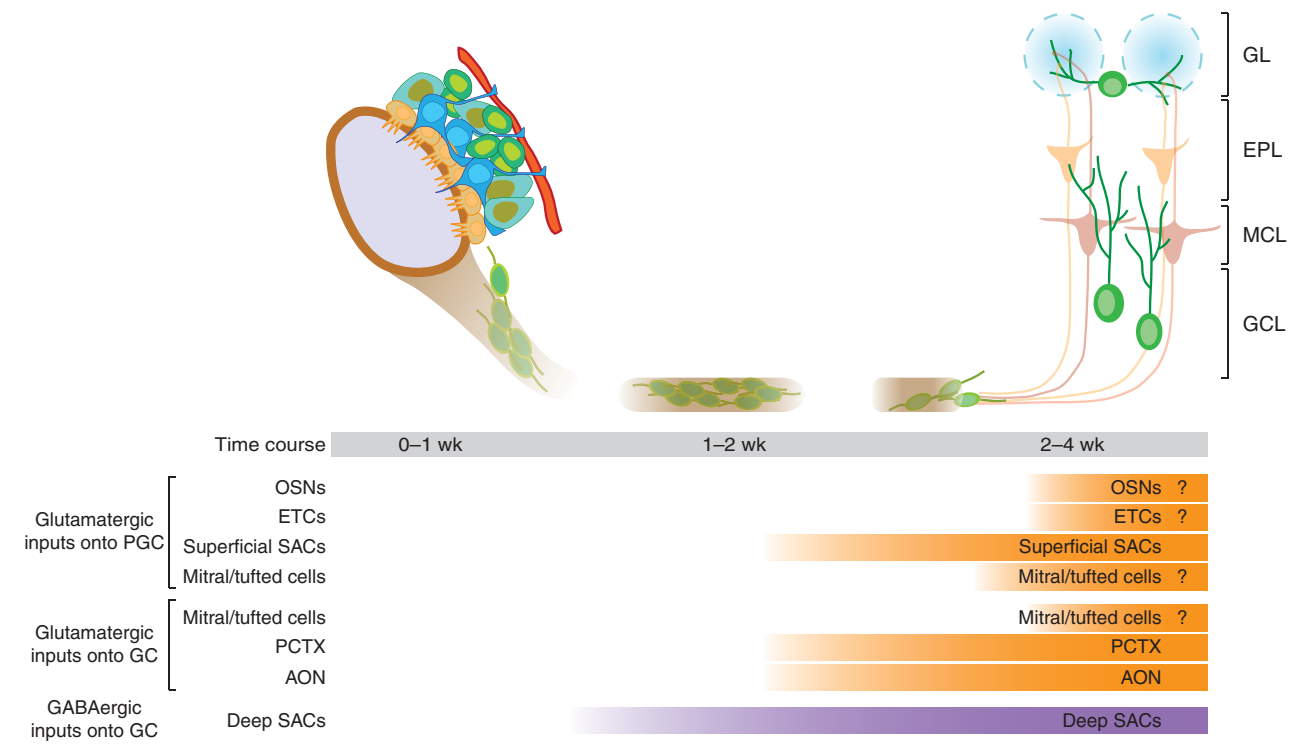

Figure 2. Circuitry regulation of adult neurogenesis in the lateral ventricles and olfactory bulb $(\mathrm{OB})$. $(A)$ A sagittal section view of an adult rodent brain highlighting the lateral ventricles and $\mathrm{OB}$. Also shown are the potential axonal projection to the OB. AON, anterior olfactory nucleus; PCTX, piriform cortex; hDB, horizontal limb of the diagonal band of Broca; RN, raphe nucleus; LC, locus coeruleus. (B) Potential inputs to subventricular zone/rostral migratory stream (SVZ/RMS) progenitors and OB interneurons. Color boxes indicate the laminar distribution of the axon terminals of these inputs. GL, glomerular layer; EPL, external plexiform layer; MCL, mitral cell layer; GCL, granule cell layer. $(C)$ Integration of newborn neurons during adult OB neurogenesis. Shown is the summary of various inputs that appear in granule cells (GCs) and periglomular cells (PGCs) in the OB during adult neurogenesis at distinct developmental stages. OSN, olfactory sensory neuron; ETC, external tufted cells; SAC, short-axon cells.

vesicular manner (Nguyen et al. 2003; Wang et al. 2003; De Marchis et al. 2004; Liu et al. 2005; Gascon et al. 2006), which suggests that they may contribute to GABAergic control of early progenitor stages. Recently, a rabiesbased transsynaptic tracing study showed that migrating neuroblasts are transiently con- tacted by some mature neurons (presumably GABAergic) located in the immediate vicinity of the SVZ/RMS, suggesting that newborn neurons in the olfactory system first receive direct inputs from local GABAergic neurons (Fig. 2C), similar to the innervation pattern of new neurons in adult SGZ. Soon after new neurons reach 
the $\mathrm{OB}$ ( $\sim 3$ wk of cell age), they become targets for the olfactory cortex controlled by corticofugal inputs. Newborn neurons in the OB become first innervated by a wide spectrum of local interneurons residing in the GCL (deep shortaxon and Blanes cells), followed by interneurons (superficial short-axon cells) in the external plexiform layer (EPL) (Fig. 2C) (Deshpande et al. 2013). Future studies targeting specific circuit components, both locally and distally, will address whether neuronal activity through distinct populations of GABAergic neurons can control SVZ neurogenesis, either directly or indirectly.

\section{Glutamatergic-SVZ/OB Circuit}

In the adult $\mathrm{OB}$, nearly all newly recruited neurons become local interneurons (Lledo et al. 2008). The majority of the new cells differentiate into GCs (Luskin et al. 1993; Lois and Alvarez-Buylla 1994). Therefore, GCs are the largest population of interneurons in the bulb (Cheng et al. 2004; Shepherd 2004), and they are also the most abundant subtype of neurons added to the adult OB (Lledo et al. 2006). So far, the glutamatergic inputs to the granule interneurons are best characterized because of their abundance and physical location (Katagiri et al. 2011). Using patch-clamp recordings and electron microscopy (EM), it has been shown that proximal excitatory inputs are the first synaptic contacts formed on developing new GCs within a few days after they reach the OB. The origin of these early glutamatergic inputs remains to be elucidated. Recent rabies virusbased retrograde synaptic tracing shows that new neurons within the anterior olfactory nucleus (AON) and the piriform cortex (PCTX) form axodendritic synapses onto the basolateral dendrites of GCs by the third week after retroviral labeling (Fig. 2C) (Deshpande et al. 2013).

Although adult-born periglomular cells (PGCs) represent a minority of adult-neurons generated from SVZ neuroblasts, they similarly show sequential and timed synaptic inputs. Briefly, PGCs receive early GABAergic inputs, followed by glutamatergic innervation from ol- factory sensory neurons (OSNs) as early as $1 \mathrm{wk}$ after retroviral injection (Grubb et al. 2008). Other glutamatergic inputs found on immature PGCs are presumably formed between this time point and the mature state. These glutamatergic inputs include those from external tufted cells and mitral/tufted cells (Panzanelli et al. 2009). Future studies on the functional contribution of these distinct inputs will add to our knowledge of how they shape the functional impact of adult neurogenesis and, as a consequence, proper circuit function.

\section{Serotonergic-SVZ/OB Circuit}

In addition to sending projections to the SGZ of the DG, serotonergic neurons from raphe nuclei also project to SVZ via the supraependymal nerve plexus (Fig. 2A) (Lorez and Richards 1982; Brezun and Daszuta 1999). It is generally thought that 5-HT has a proneurogenic effect on SVZ neurogenesis. Indeed, the in vivo application of 5-HT results in increased SVZ neurogenesis (Hitoshi et al. 2007). Agonists of $5-\mathrm{HT}_{1 \mathrm{~A}}$ and $5-\mathrm{HT}_{2 \mathrm{C}}$ receptors increase NPC proliferation (Banasr et al. 2004; Soumier et al. 2010), whereas $5-\mathrm{HT}_{1 \mathrm{~B}}$ receptor activation decreases NPC proliferation (Banasr et al. 2004). They likely act at different points of the local circuit, as $5-\mathrm{HT}_{1 \mathrm{~A}}$ receptors are auto-inhibitory, whereas $5-\mathrm{HT}_{2 \mathrm{C}}$ receptors contribute to membrane depolarization and subsequent excitation of the postsynaptic neuron. Additionally, as in the SGZ, $5 \mathrm{HT}_{1 \mathrm{~A}}$ antagonizing antidepressants are proneurogenic (Ohira et al. 2013). Taken together, these findings emphasize the complex nature of serotonergic signaling in neurogenesis. It is yet to be determined whether these effects are mediated through direct activation of 5-HT receptors on NSC and their progeny or indirectly through receptor activation on cells in the adjacent area to the SVZ in the lateral ventricle (Soumier et al. 2010). In addition, ablation of raphe nuclei results in decreased NPC proliferation (Brezun and Daszuta 1999; Banasr et al. 2004). Whether 5-HT regulates later stages of adult neurogenesis, such as synaptic integration, still awaits further investigation. 
J. Song et al.

\section{Dopaminergic-SVZ/OB Circuit}

Dopaminergic neurons from the substantia nigra have been shown to project to the SVZ region (Baker et al. 2004; Höglinger et al. 2004; Freundlieb et al. 2006; Winner et al. 2006). In addition, postmortem studies in humans have identified dopaminergic fibers in contact with epidermal growth factor receptor positive cells in the SVZ, which are presumably proliferating progenitors (Höglinger et al. 2004). Accumulating evidence suggests that DA signaling has an impact on SVZ neurogenesis at several developmental stages. Pharmacological manipulations using agonists or antagonists of selective DA receptors have led to significant increases and decreases in the number of proliferating progenitors in the SVZ (Van Kampen et al. 2004; Kippin et al. 2005; Kim et al. 2010). Furthermore, activation of D2 or D3 receptors has been shown to enhance the maturation and differentiation of neural progenitors into neurons in the SVZ/OB (Feron et al. 1999; Van Kampen et al. 2004). In contrast, ablation of dopaminergic inputs from substantia nigra resulted in decreased neural progenitor proliferation, neuroblast migration and the number of differentiated new neurons in the OB (Baker et al. 2004; Höglinger et al. 2004; Freundlieb et al. 2006; O'Keeffe et al. 2009a,b; Cova et al. 2010). Furthermore, activation of D2 or D3 receptors has been shown to enhance the maturation and differentiation of neural progenitors into neurons in the SVZ/OB. Like other neuromodulators, the regulatory influence on the neurogenic niche of the SVZ by subcortical dopaminergic nuclei is in need of extensive investigation.

\section{CIRCUITRY INTERACTION IN REGULATION OF ADULT NEUROGENESIS}

Adult neurogenesis is subject to complex extrinsic regulation. From many of the aforementioned studies, a picture starts to emerge that neural precursor cells and their progeny can be directly influenced by both local and distal circuitry, or indirectly influenced by interactions of such networks. Systems outside of the neurogenic microenvironment that are connected to circuitries within the neurogenic niche are known to extensively interact. The influence of neuromodulatory systems may not be direct, and the extensive innervation of other brain regions further complicates the consequences of specific activity by these systems. Because of the flexibility and apparent precision with which neurogenesis is regulated by particular environmental influence and experience, layers of regulation are likely. Here, we discuss some of the complex interactions of different neuromodulatory systems from, and how such complex and dynamic interactions could potentially impact adult neurogenesis.

In the SGZ/hippocampus, GABA release from local hippocampal GABAergic interneurons can be regulated by a wide variety of neurotransmitters and neuromodulators, including glutamate from the EC, serotonin from the raphe nuclei (Matsuyama et al. 1997), and ACh from the MSDB (Tozuka et al. 2005; Griguoli and Cherubini 2012; Teles-Grilo Ruivo and Mellor 2013). The excitatory glutamatergic inputs from EC forms synapses with GCs as well as local interneurons in the molecular layer of the DG. For example, in the adult DG, $\mathrm{PV}^{+}$ interneurons receive their major excitatory inputs from dentate GCs and, to a lesser extent, from EC inputs (Seress et al. 2001). Therefore, it is conceivable that local interneuron activity may be regulated by both local GC inputs and distal EC inputs in response to network activity. Similarly, serotonergic and cholinergic projections can directly innervate distinct local interneurons and also indirectly regulate local interneuron activity through GCs. Given that local interneurons can regulate quiescent neural-stem-cell activation and fate decision as well as proliferating neural progenitor survival (Song et al. 2012b, 2013), altering neuronal activity of those projection neurons that interact with local interneurons is likely to play a critical role in regulating adult hippocampal neurogenesis.

Interestingly, some cells of the raphe nuclei send collateral projections to both the septal nuclei and the DG (McKenna and Vertes 2001). Serotonin application onto slices from the MSDB exerts inhibitory effects on both cho- 
linergic and noncholinergic neurons. Serotonin was found to directly excite GABAergic cells of these nuclei (Alreja 1996), presumably via action on $5 \mathrm{HT}_{2 \mathrm{~A}}$, and $5 \mathrm{HT}_{3 / 4}$ type receptors. Because the septum sends both cholinergic and GABAergic projections to the DG, serotonergic signaling may directly influence the activity of the cholinergic system itself. The interaction of these two systems, involved in modulating adult neurogenesis through poorly understood mechanisms, provides another layer of complexity in establishing the influence of long-range projections on local hippocampal circuitry.

For the SVZ region, although there are no direct cholinergic inputs reported in the SVZ, lesions of forebrain cholinergic inputs decrease the number of newly born neurons in the $\mathrm{OB}$, suggesting the indirect action of the cholinergic system on SVZ neurogenic processes. In addition, ACh is known to regulate DA release in the striatum by regulating the firing of dopaminergic neurons in the substantia nigra (Aosaki et al. 2009; Lester et al. 2010). It is thus conceivable that ACh could indirectly regulate SVZ NPC proliferation through the modulation of DA release, given that DA is proposed to exert a direct effect on SVZ neurogenesis.

In summary, neuronal circuits that regulate distinct stages of adult neurogenesis are dynamic and complex. Building on the exciting recent progress and development of new tools to study neuronal circuits, the field is poised to make major breakthroughs in understanding activity-dependent regulation of distinct adult neurogenesis processes. A number of genetic models have been developed that allow targeting of specific subtypes of neural progenitors or newborn neurons at specific maturation stages. Optogenetic approaches permit manipulating the activity of adult-born neurons with exquisite spatial and temporal precision and without the complication of injury responses and homeostatic compensation associated with the physical elimination of adult neurogenesis. The cross-synaptic tracing approach provides precise mapping of the circuitry from the neuron type of interest. With a combination of these approaches, future studies will clarify how adult neurogenesis is directly and indirectly regulated by local and distal circuits.

\section{CONCLUSION}

Significant progress has been made over the past decade in the study of almost every aspect of adult neurogenesis in the mammalian central nervous system. Aided by methodological advancements, studies have started to extensively investigate circuit-based regulation of adult neurogenesis. Building or altering a circuit requires the orchestration of processes that control the activation of NSCs, the number of neurons being produced, their migration, and their morphogenesis to form proper synaptic connections. A unique feature of this circuit is the large-scale structural modification via the addition of newborn neurons arising from ongoing neurogenesis. The entire milieu must preserve the functional integrity of the existing circuitry, and, at the same time, it needs to provide a niche to support the development of adult-born neurons and allow these cells to modify the local neuronal network. Defects in one or several of these mechanisms will lead to circuit abnormalities, such as those associated with altered excitability and behavioral defects (Zhou et al. 2013).

Adult neurogenesis occurs throughout life in the DG of the hippocampus and contributes to specific brain functions. Different from other somatic stem-cell compartments, in which morphogens and growth factors generally serve as niche signals, adult neurogenesis is well known to be dynamically regulated by neuronal activity and experience. Adult-born GCs in the adult hippocampus receive major synaptic inputs from the EC and local inhibitory interneurons (van Praag et al. 2002; Overstreet Wadiche et al. 2005; Laplagne et al. 2006) and form functional synapses with interneurons and CA3 pyramidal cells (Toni et al. 2008). The integration of new neurons into the existing neural circuitry endows them with the capacity to impact hippocampal function. A strong correlation between adult neurogenesis and performance in hippocampus-dependent learning tasks suggests that the occurrence of neurogenesis requires exquisite regulatory control and mechanisms 
J. Song et al.

for intervention by multiple neuromodulatory systems (Saxe et al. 2006; Dupret et al. 2008; Imayoshi et al. 2008; Clelland et al. 2009; Shors et al. 2012). The differential modulation by various types of local and distal circuits thus may provide the fine control of synaptic integration of adult-born neurons required for specific neurogenic events in response to experiences, environmental influence, and pathological conditions. A recent study showed that $\mathrm{PV}^{+}$interneurons contribute to social isolation-induced activation and symmetric cell division of quiescent NSCs, and the long-term consequences of such experience contribute to decreased adult neurogenesis (Song et al. 2012b). Although the causal link between decreased neurogenesis and animal behaviors has not been established, it is likely that decreased adult neurogenesis partially contributes to animals' affective behaviors. Thus, this study presents an example that decreased local interneuron activity results in decreased neuronal production, which could, in turn, contribute to abnormal behaviors linked to aberrant circuitry activity. Another example is that dysfunctional neurogenesis resulting from GABAergic interneuron pathology in mice models of $\mathrm{Alz}$ heimer's disease may in turn exacerbate neuronal vulnerability to the disease and contribute to memory impairment (Li et al. 2009a; Sun et al. 2009).

Currently, our understanding of what makes the two neurogenic regions receptive to the integration of de novo neuronal populations in the adult brain is very limited. For example, brain injuries, such as stroke or ischemia, can induce adult neural progenitor proliferation and new neuron migration to distal injury sites; however, the majority of these new neurons fails to integrate into the local circuitry and do not survive over the long term (Parent 2003). Similarly, transplanted neural progenitors or immature neurons in the adult brain rarely functionally integrate and often die (Herrera et al. 1999; Isacson 2003). Therefore, identifying critical features of the neurogenic niche that foster integration and survival of newborn progeny may lead to novel strategies to enhance functional repair from endogenous or transplanted neu- rons after injury or degenerative neurological disorders.

\section{ACKNOWLEDGMENTS}

The research in the authors' laboratories was supported by University of North Carolina (UNC) start-up fund (J.S.), National Alliance for Research on Schizophrenia and Depression (NARSAD) (J.S., G.-1.M.), American Heart Association (J.S.), Whitehall Foundation (J.S.), National Institutes of Health (NIH) (R21MH106939 to J.S.), UNC Pharmacology T32 Training Grant (R.H.J.O.), Simons Foundation Autism Research Initiative (SFARI) (H.S.), NIH (NS048271, HD069184 to G.-l.M. and NS047344, ES021957 to H.S.), the Dr. Miriam and Sheldon G. Adelson Medical Research Foundation (G.-1.M.), and Maryland Stem Cell Research Fund (J.S., G.-1.M.). The authors acknowledge the joint participation by the Diana Helis Henry Medical Research Foundation through its direct engagement in the continuous active conduct of medical research in conjunction with The Johns Hopkins Hospital and the Johns Hopkins University School of Medicine and the Foundation's Parkinson's Disease Program No. H-1 (to G.-1.M.).

\section{REFERENCES}

Alreja M. 1996. Excitatory actions of serotonin on GABAergic neurons of the medial septum and diagonal band of Broca. Synapse 22: 15-27.

Alvarez-Buylla A, Lim DA. 2004. For the long run: Maintaining germinal niches in the adult brain. Neuron 41: 683-686.

Amaral DG, Scharfman HE, Lavenex P. 2007. The dentate gyrus: Fundamental neuroanatomical organization (dentate gyrus for dummies). Prog Brain Res 163: 3-22.

Aosaki T, Miura M, Masuda M. 2009. Physiological interaction between acetylcholine and dopamine in the striatum. Brain Nerve 61: 373-380.

Arenkiel BR, Hasegawa H, Yi JJ, Larsen RS, Wallace ML, Philpot BD, Wang F, Ehlers MD. 2011. Activity-induced remodeling of olfactory bulb microcircuits revealed by monosynaptic tracing. PLoS ONE 6: e29423.

Baker SA, Baker KA, Hagg T. 2004. Dopaminergic nigrostriatal projections regulate neural precursor proliferation in the adult mouse subventricular zone. Eur J Neurosci 20: $575-579$.

Banasr M, Hery M, Printemps R, Daszuta A. 2004. Serotonin-induced increases in adult cell proliferation and neu- 
rogenesis are mediated through different and common 5 -HT receptor subtypes in the dentate gyrus and the subventricular zone. Neuropsychopharmacology 29: 450460.

Bardy C, Alonso M, Bouthour W, Lledo PM. 2010. How, when, and where new inhibitory neurons release neurotransmitters in the adult olfactory bulb. J Neurosci 30: 17023-17034.

Barnes NM, Sharp T. 1999. A review of central 5-HT receptors and their function. Neuropharmacology 38: 10831152.

Bartus RT, Dean RL III, Beer B, Lippa AS. 1982. The cholinergic hypothesis of geriatric memory dysfunction. Science 217: 408-414.

Bjarkam CR, Sorensen JC, Geneser FA. 2003. Distribution and morphology of serotonin-immunoreactive axons in the hippocampal region of the New Zealand white rabbit. I: Area dentata and hippocampus. Hippocampus 13: $21-37$.

Bolteus AJ, Bordey A. 2004. GABA release and uptake regulate neuronal precursor migration in the postnatal subventricular zone. J Neurosci 24: 7623-7631.

Bonaguidi MA, Wheeler MA, Shapiro JS, Stadel RP, Sun GJ, Ming GL, Song H. 2011. In vivo clonal analysis reveals self-renewing and multipotent adult neural stem cell characteristics. Cell 145: 1142-1155.

Bordey A. 2006. Adult neurogenesis: Basic concepts of signaling. Cell Cycle 5: 722-728.

Bordey A. 2007. Enigmatic GABAergic networks in adult neurogenic zones. Brain Res Rev 53: 124-134.

Brezun JM, Daszuta A. 1999. Depletion in serotonin decreases neurogenesis in the dentate gyrus and the subventricular zone of adult rats. Neuroscience 89: 999-1002.

Bruel-Jungerman E, Davis S, Rampon C, Laroche S. 2006. Long-term potentiation enhances neurogenesis in the adult dentate gyrus. J Neurosci 26: 5888-5893.

Buckmaster PS, Jongen-Relo AL. 1999. Highly specific neuron loss preserves lateral inhibitory circuits in the dentate gyrus of kainate-induced epileptic rats. J Neurosci 19: 9519-9529.

Buckmaster PS, Wenzel HJ, Kunkel DD, Schwartzkroin PA. 1996. Axon arbors and synaptic connections of hippocampal mossy cells in the rat in vivo. J Comp Neurol 366: 271-292.

Buckmaster PS, Zhang GF, Yamawaki R. 2002. Axon sprouting in a model of temporal lobe epilepsy creates a predominantly excitatory feedback circuit. J Neurosci 22: 6650-6658.

Campbell NR, Fernandes CC, Halff AW, Berg DK. 2010. Endogenous signaling through $\alpha 7$-containing nicotinic receptors promotes maturation and integration of adultborn neurons in the hippocampus. J Neurosci 30: 87348744.

Cheng L, Arata A, Mizuguchi R, Qian Y, Karunaratne A, Gray PA, Arata S, Shirasawa S, Bouchard M, Luo P, et al. 2004. Tlx3 and $T l x 1$ are post-mitotic selector genes determining glutamatergic over GABAergic cell fates. Nat Neurosci 7: 510-517.

Chun SK, Sun W, Park JJ, Jung MW. 2006. Enhanced proliferation of progenitor cells following long-term poten- tiation induction in the rat dentate gyrus. Neurobiol Learn Mem 86: 322-329.

Claiborne BJ, Amaral DG, Cowan WM. 1986. A light and electron microscopic analysis of the mossy fibers of the rat dentate gyrus. J Comp Neurol 246: 435-458.

Clelland CD, Choi M, Romberg C, Clemenson GD Jr, Fragniere A, Tyers P, Jessberger S, Saksida LM, Barker RA, Gage FH, et al. 2009. A functional role for adult hippocampal neurogenesis in spatial pattern separation. Science 325: 210-213.

Clemett DA, Punhani T, Duxon MS, Blackburn TP, Fone KC. 2000. Immunohistochemical localisation of the 5-HT2C receptor protein in the rat CNS. Neuropharmacology 39: $123-132$.

Cooper-Kuhn CM, Winkler J, Kuhn HG. 2004. Decreased neurogenesis after cholinergic forebrain lesion in the adult rat. J Neurosci Res 77: 155-165.

Cova L, Armentero MT, Zennaro E, Calzarossa C, Bossolasco P, Busca G, Lambertenghi Deliliers G, Polli E, Nappi G, Silani V, et al. 2010. Multiple neurogenic and neurorescue effects of human mesenchymal stem cell after transplantation in an experimental model of Parkinson's disease. Brain Res 1311: 12-27.

De Marchis S, Temoney S, Erdelyi F, Bovetti S, Bovolin P, Szabo G, Puche AC. 2004. GABAergic phenotypic differentiation of a subpopulation of subventricular derived migrating progenitors. Eur J Neurosci 20: 1307-1317.

Deshpande A, Bergami M, Ghanem A, Conzelmann KK, Lepier A, Gotz M, Berninger B. 2013. Retrograde monosynaptic tracing reveals the temporal evolution of inputs onto new neurons in the adult dentate gyrus and olfactory bulb. Proc Natl Acad Sci 110: E1152-E1161.

Djavadian RL. 2004. Serotonin and neurogenesis in the hippocampal dentate gyrus of adult mammals. Acta Neurobiol Exp (Wars) 64: 189-200.

Djavadian RL, Wielkopolska E, Bialoskorska K, Turlejski K. 1999. Localization of the 5-HT1A receptors in the brain of opossum Monodelphis domestica. Neuroreport 10: 3195-3200.

Duan X, Kang E, Liu CY, Ming GL, Song H. 2008. Development of neural stem cell in the adult brain. Curr Opin Neurobiol 18: 108-115.

Dupret D, Pleydell-Bouverie B, Csicsvari J. 2008. Inhibitory interneurons and network oscillations. Proc Natl Acad Sci 105: 18079-18080.

Duveau V, Laustela S, Barth L, Gianolini F, Vogt KE, Keist R, Chandra D, Homanics GE, Rudolph U, Fritschy JM. 2011. Spatiotemporal specificity of $\mathrm{GABA}_{\mathrm{A}}$ receptormediated regulation of adult hippocampal neurogenesis. Eur J Neurosci 34: 362-373.

el Mestikawy S, Taussig D, Gozlan H, Emerit MB, Ponchant M, Hamon M. 1989. Chromatographic analyses of the serotonin 5-HT1A receptor solubilized from the rat hippocampus. J Neurochem 53: 1555-1566.

Ferguson SM, Neumaier JF. 2012. Grateful DREADDs: Engineered receptors reveal how neural circuits regulate behavior. Neuropsychopharmacology 37: 296-297.

Feron F, Vincent A, Mackay-Sim A. 1999. Dopamine promotes differentiation of olfactory neuron in vitro. Brain Res 845: 252-259. 
J. Song et al.

Freund TF, Buzsaki G. 1996. Interneurons of the hippocampus. Hippocampus 6: 347-470.

Freundlieb N, Francois C, Tande D, Oertel WH, Hirsch EC, Höglinger GU. 2006. Dopaminergic substantia nigra neurons project topographically organized to the subventricular zone and stimulate precursor cell proliferation in aged primates. J Neurosci 26: 2321-2325.

Frotscher M, Vida I, Bender R. 2000. Evidence for the existence of non-GABAergic, cholinergic interneurons in the rodent hippocampus. Neuroscience 96: 27-31.

Gage FH. 2000. Mammalian neural stem cells. Science 287: $1433-1438$.

Gasbarri A, Sulli A, Packard MG. 1997. The dopaminergic mesencephalic projections to the hippocampal formation in the rat. Prog Neuropsychopharmacol Biol Psychiatry 21: 1-22.

Gascon E, Dayer AG, Sauvain MO, Potter G, Jenny B, De Roo M, Zgraggen E, Demaurex N, Muller D, Kiss JZ. 2006. GABA regulates dendritic growth by stabilizing lamellipodia in newly generated interneurons of the olfactory bulb. J Neurosci 26: 12956-12966.

Ge S, Goh EL, Sailor KA, Kitabatake Y, Ming GL, Song H. 2006. GABA regulates synaptic integration of newly generated neurons in the adult brain. Nature 439: 589-593.

Ge S, Yang CH, Hsu KS, Ming GL, Song H. 2007. A critical period for enhanced synaptic plasticity in newly generated neurons of the adult brain. Neuron 54: 559-566.

Ge S, Sailor KA, Ming GL, Song H. 2008. Synaptic integration and plasticity of new neurons in the adult hippocampus. J Physiol 586: 3759-3765.

Goldman SA, Chen Z. 2011. Perivascular instruction of cell genesis and fate in the adult brain. Nat Neurosci 14: $1382-1389$.

Griguoli M, Cherubini E. 2012. Regulation of hippocampal inhibitory circuits by nicotinic acetylcholine receptors. J Physiol 590: 655-666.

Grubb MS, Nissant A, Murray K, Lledo PM. 2008. Functional maturation of the first synapse in olfaction: Development and adult neurogenesis. J Neurosci 28: 29192932.

Halasy K, Somogyi P. 1993. Subdivisions in the multiple GABAergic innervation of granule cells in the dentate gyrus of the rat hippocampus. Eur J Neurosci 5: 411-429.

Han ZS, Buhl EH, Lorinczi Z, Somogyi P. 1993. A high degree of spatial selectivity in the axonal and dendritic domains of physiologically identified local-circuit neurons in the dentate gyrus of the rat hippocampus. Eur $J$ Neurosci 5: 395-410.

Herrera DG, Garcia-Verdugo JM, Alvarez-Buylla A. 1999. Adult-derived neural precursors transplanted into multiple regions in the adult brain. Ann Neurol 46: 867-877.

Hitoshi S, Maruta N, Higashi M, Kumar A, Kato N, Ikenaka K. 2007. Antidepressant drugs reverse the loss of adult neural stem cells following chronic stress. J Neurosci Res 85: 3574-3585.

Höglinger GU, Rizk P, Muriel MP, Duyckaerts C, Oertel WH, Caille I, Hirsch EC. 2004. Dopamine depletion impairs precursor cell proliferation in Parkinson disease. Nat Neurosci 7: 726-735.
Houser CR. 2007. Interneurons of the dentate gyrus: An overview of cell types, terminal fields and neurochemical identity. Prog Brain Res 163: 217-232.

Ihrie RA, Alvarez-Buylla A. 2011. Lake-front property: A unique germinal niche by the lateral ventricles of the adult brain. Neuron 70: 674-686.

Imayoshi I, Sakamoto M, Ohtsuka T, Takao K, Miyakawa T, Yamaguchi M, Mori K, Ikeda T, Itohara S, Kageyama R. 2008. Roles of continuous neurogenesis in the structural and functional integrity of the adult forebrain. $\mathrm{Nat} \mathrm{Neu}-$ rosci 11: 1153-1161.

Isacson O. 2003. The production and use of cells as therapeutic agents in neurodegenerative diseases. Lancet Neurol 2: 417-424.

Itou Y, Nochi R, Kuribayashi H, Saito Y, Hisatsune T. 2011. Cholinergic activation of hippocampal neural stem cells in aged dentate gyrus. Hippocampus 21: 446-459.

Jagasia R, Steib K, Englberger E, Herold S, Faus-Kessler T, Saxe M, Gage FH, Song H, Lie DC. 2009. GABA-cAMP response element-binding protein signaling regulates maturation and survival of newly generated neurons in the adult hippocampus. J Neurosci 29: 7966-7977.

Jang MH, Song H, Ming Gl. 2008. Regulation of adult neurogenesis by neurotransmitters. In Adult neurogenesis (ed. Gage FH, Kempermann G, Song H). Cold Spring Harbor Laboratory Press, Cold Spring Harbor, NY.

Jang MH, Bonaguidi MA, Kitabatake Y, Sun J, Song J, Kang E, Jun H, Zhong C, Su Y, Guo JU, et al. 2013. Secreted frizzled-related protein 3 regulates activity-dependent adult hippocampal neurogenesis. Cell Stem Cell 12: 215-223.

Jha S, Rajendran R, Davda J, Vaidya VA. 2006. Selective serotonin depletion does not regulate hippocampal neurogenesis in the adult rat brain: Differential effects of $p$-chlorophenylalanine and 5,7-dihydroxytryptamine. Brain Res 1075: 48-59.

Kaneko N, Okano H, Sawamoto K. 2006. Role of the cholinergic system in regulating survival of newborn neurons in the adult mouse dentate gyrus and olfactory bulb. Genes Cells 11: 1145-1159.

Katagiri H, Pallotto M, Nissant A, Murray K, Sassoe-Pognetto M, Lledo PM. 2011. Dynamic development of the first synapse impinging on adult-born neurons in the olfactory bulb circuit. Neural Syst Circuits 1: 6 .

Kempermann G, Gage FH. 1999. New nerve cells for the adult brain. Sci Am 280: 48-53.

Kempermann G, Kuhn HG, Gage FH. 1997. More hippocampal neurons in adult mice living in an enriched environment. Nature 386: 493-495.

Kempermann G, Jessberger S, Steiner B, Kronenberg G. 2004. Milestones of neuronal development in the adult hippocampus. Trends Neurosci 27: 447-452.

Kim Y, Wang WZ, Comte I, Pastrana E, Tran PB, Brown J, Miller RJ, Doetsch F, Molnar Z, Szele FG. 2010. Dopamine stimulation of postnatal murine subventricular zone neurogenesis via the D3 receptor. $J$ Neurochem 114: $750-760$

Kinsey AM, Wainwright A, Heavens R, Sirinathsinghji DJ, Oliver KR. 2001. Distribution of 5-ht ${ }_{5 \mathrm{~A}}, 5-\mathrm{ht}_{5 \mathrm{~B}}, 5-\mathrm{ht}_{6}$ and $5-\mathrm{HT}_{7}$ receptor mRNAs in the rat brain. Brain Res Mol Brain Res 88: 194-198. 
Kippin TE, Kapur S, van der Kooy D. 2005. Dopamine specifically inhibits forebrain neural stem cell proliferation, suggesting a novel effect of antipsychotic drugs. J Neurosci 25: 5815-5823.

Kohler C. 1986. Intrinsic connections of the retrohippocampal region in the rat brain. II: The medial entorhinal area. J Comp Neurol 246: 149-169.

Kriegstein A, Alvarez-Buylla A. 2009. The glial nature of embryonic and adult neural stem cells. Annu Rev Neurosci 32: $149-184$.

Kumamoto N, Gu Y, Wang J, Janoschka S, Takemaru K, Levine J, Ge S. 2012. A role for primary cilia in glutamatergic synaptic integration of adult-born neurons. Nat Neurosci 15: 399-405.

Laplagne DA, Esposito MS, Piatti VC, Morgenstern NA, Zhao C, van Praag H, Gage FH, Schinder AF. 2006. Functional convergence of neurons generated in the developing and adult hippocampus. PLoS Biol 4: e409.

Lester DB, Rogers TD, Blaha CD. 2010. Acetylcholine-dopamine interactions in the pathophysiology and treatment of CNS disorders. CNS Neurosci Ther 16: 137-162.

Li G, Bien-Ly N, Andrews-Zwilling Y, Xu Q, Bernardo A, Ring K, Halabisky B, Deng C, Mahley RW, Huang Y. 2009a. GABAergic interneuron dysfunction impairs hippocampal neurogenesis in adult apolipoprotein E4 knockin mice. Cell Stem Cell 5: 634-645.

Li Y, Mu Y, Gage FH. 2009b. Development of neural circuits in the adult hippocampus. Curr Top Dev Biol 87: 149174.

Liu J, Shi Y, Tang W, Guo T, Li D, Yang Y, Zhao X, Wang H, Li $X$, Feng G, et al. 2005. Positive association of the human $\mathrm{GABA}_{\mathrm{A}}$-receptor $\beta 2$ subunit gene haplotype with schizophrenia in the Chinese Han population. Biochem Biophys Res Commun 334: 817-823.

Lledo PM, Alonso M, Grubb MS. 2006. Adult neurogenesis and functional plasticity in neuronal circuits. Nat Rev Neurosci 7: 179-193.

Lledo PM, Merkle FT, Alvarez-Buylla A. 2008. Origin and function of olfactory bulb interneuron diversity. Trends Neurosci 31: 392-400.

Lois C, Alvarez-Buylla A. 1994. Long-distance neuronal migration in the adult mammalian brain. Science 264: 1145-1148.

Lois C, Garcia-Verdugo JM, Alvarez-Buylla A. 1996. Chain migration of neuronal precursors. Science 271: 978-981.

Lorez HP, Richards JG. 1982. Supra-ependymal serotoninergic nerves in mammalian brain: Morphological, pharmacological and functional studies. Brain Res Bull 9: 727-741.

Lubke J, Deller T, Frotscher M. 1997. Septal innervation of mossy cells in the hilus of the rat dentate gyrus: An anterograde tracing and intracellular labeling study. Exp Brain Res 114: 423-432.

Luskin MB, Parnavelas JG, Barfield JA. 1993. Neurons, astrocytes, and oligodendrocytes of the rat cerebral cortex originate from separate progenitor cells: An ultrastructural analysis of clonally related cells. J Neurosci 13: 1730-1750.

Ma DK, Ming GL, Song H. 2005. Glial influences on neural stem cell development: Cellular niches for adult neurogenesis. Curr Opin Neurobiol 15: 514-520.
Ma DK, Bonaguidi MA, Ming GL, Song H. 2009a. Adult neural stem cells in the mammalian central nervous system. Cell Res 19: 672-682.

Ma DK, Jang MH, Guo JU, Kitabatake Y, Chang ML, PowAnpongkul N, Flavell RA, Lu B, Ming GL, Song H. 2009b. Neuronal activity-induced Gadd45b promotes epigenetic DNA demethylation and adult neurogenesis. Science 323: 1074-1077.

Ma DK, Kim WR, Ming GL, Song H. 2009c. Activity-dependent extrinsic regulation of adult olfactory bulb and hippocampal neurogenesis. Ann NY Acad Sci 1170: 664-673.

Maccaferri G, Lacaille JC. 2003. Interneuron diversity series: Hippocampal interneuron classifications-Making things as simple as possible, not simpler. Trends Neurosci 26: 564-571.

Malberg JE, Eisch AJ, Nestler EJ, Duman RS. 2000. Chronic antidepressant treatment increases neurogenesis in adult rat hippocampus. J Neurosci 20: 9104-9110.

Markwardt SJ, Wadiche JI, Overstreet-Wadiche LS. 2009. Input-specific GABAergic signaling to newborn neurons in adult dentate gyrus. J Neurosci 29: 15063-15072.

Markwardt SJ, Dieni CV, Wadiche JI, Overstreet-Wadiche L. 2011. Ivy/neurogliaform interneurons coordinate activity in the neurogenic niche. Nat Neurosci 14: 1407-1409.

Marques-Mari AI, Nacher J, Crespo C, Gutierrez-Mecinas M, Martinez-Guijarro FJ, Blasco-Ibanez JM. 2007. Loss of input from the mossy cells blocks maturation of newly generated granule cells. Hippocampus 17: 510-524.

Masiulis I, Yun S, Eisch AJ. 2011. The interesting interplay between interneurons and adult hippocampal neurogenesis. Mol Neurobiol 44: 287-302.

Matsuyama S, Nei K, Tanaka C. 1997. Regulation of GABA release via NMDA and 5-HT1A receptors in guinea pig dentate gyrus. Brain Res 761: 105-112.

McKenna JT, Vertes RP. 2001. Collateral projections from the median raphe nucleus to the medial septum and hippocampus. Brain Res Bull 54: 619-630.

Miller FD, Gauthier-Fisher A. 2009. Home at last: Neural stem cell niches defined. Cell Stem Cell 4: 507-510.

Ming GL, Song H. 2011. Adult neurogenesis in the mammalian brain: Significant answers and significant questions. Neuron 70: 687-702.

Moore RY, Halaris AE. 1975. Hippocampal innervation by serotonin neurons of the midbrain raphe in the rat. $J$ Comp Neurol 164: 171-183.

Moreno-Lopez B, Noval JA, Gonzalez-Bonet LG, Estrada C. 2000. Morphological bases for a role of nitric oxide in adult neurogenesis. Brain Res 869: 244-250.

$\mathrm{Mu}$ Y, Zhao C, Gage FH. 2011. Dopaminergic modulation of cortical inputs during maturation of adult-born dentate granule cells. J Neurosci 31: 4113-4123.

Murphy BL, Danzer SC. 2011. Somatic translocation: A novel mechanism of granule cell dendritic dysmorphogenesis and dispersion. J Neurosci 31: 2959-2964.

Nguyen L, Malgrange B, Breuskin I, Bettendorff L, Moonen G, Belachew S, Rigo JM. 2003. Autocrine/paracrine activation of the $\mathrm{GABA}_{\mathrm{A}}$ receptor inhibits the proliferation of neurogenic polysialylated neural cell adhesion moleculepositive $\left(\mathrm{PSA}^{-\mathrm{NCAM}^{+}}\right)^{2}$ precursor cells from postnatal striatum. J Neurosci 23: 3278-3294. 
J. Song et al.

Ninkovic J, Gotz M. 2007. Signaling in adult neurogenesis: From stem cell niche to neuronal networks. Curr Opin Neurobiol 17: 338-344.

Ohira K, Takeuchi R, Shoji H, Miyakawa T. 2013. Fluoxetine-induced cortical adult neurogenesis. Neuropsychopharmacology 38: 909-920.

O’Keeffe GC, Barker RA, Caldwell MA. 2009a. Dopaminergic modulation of neurogenesis in the subventricular zone of the adult brain. Cell Cycle 8: 2888-2894.

O'Keeffe GC, Tyers P, Aarsland D, Dalley JW, Barker RA, Caldwell MA. 2009b. Dopamine-induced proliferation of adult neural precursor cells in the mammalian subventricular zone is mediated through EGF. Proc Natl Acad Sci 106: 8754-8759.

Overstreet LS, Hentges ST, Bumaschny VF, de Souza FS, Smart JL, Santangelo AM, Low MJ, Westbrook GL, Rubinstein M. 2004. A transgenic marker for newly born granule cells in dentate gyrus. J Neurosci 24: 3251-3259.

Overstreet Wadiche L, Bromberg DA, Bensen AL, Westbrook GL. 2005. GABAergic signaling to newborn neurons in dentate gyrus. J Neurophysiol 94: 4528-4532.

Panzanelli P, Bardy C, Nissant A, Pallotto M, Sassoe-Pognetto M, Lledo PM, Fritschy JM. 2009. Early synapse formation in developing interneurons of the adult olfactory bulb. J Neurosci 29: 15039-15052.

Parent JM. 2003. Injury-induced neurogenesis in the adult mammalian brain. Neuroscientist 9: 261-272.

Park JH, Enikolopov G. 2010. Transient elevation of adult hippocampal neurogenesis after dopamine depletion. Exp Neurology 222: 267-276.

Platel JC, Lacar B, Bordey A. 2007. GABA and glutamate signaling: Homeostatic control of adult forebrain neurogenesis. J Mol Histol 38: 303-311.

Platel JC, Dave KA, Bordey A. 2008. Control of neuroblast production and migration by converging GABA and glutamate signals in the postnatal forebrain. J Physiol 586: 3739-3743.

Radley JJ, Jacobs BL. 2002. 5-HT1A receptor antagonist administration decreases cell proliferation in the dentate gyrus. Brain Res 955: 264-267.

Sahay A, Wilson DA, Hen R. 2011. Pattern separation: A common function for new neurons in hippocampus and olfactory bulb. Neuron 70: $582-588$.

Saxe MD, Battaglia F, Wang JW, Malleret G, David DJ, Monckton JE, Garcia AD, Sofroniew MV, Kandel ER, Santarelli L, et al. 2006. Ablation of hippocampal neurogenesis impairs contextual fear conditioning and synaptic plasticity in the dentate gyrus. Proc Natl Acad Sci 103: 17501-17506.

Schmidt-Hieber C, Jonas P, Bischofberger J. 2004. Enhanced synaptic plasticity in newly generated granule cells of the adult hippocampus. Nature 429: 184-187.

Seress L, Abraham H, Paleszter M, Gallyas F. 2001. Granule cells are the main source of excitatory input to a subpopulation of GABAergic hippocampal neurons as revealed by electron microscopic double staining for zinc histochemistry and parvalbumin immunocytochemistry. Exp Brain Res 136: 456-462.

Shepherd GM. 2004. The synaptic organization of the brain, 5th ed. Oxford University Press, New York.
Shors TJ, Anderson ML, Curlik DM II, Nokia MS. 2012. Use it or lose it: How neurogenesis keeps the brain fit for learning. Behav Brain Res 227: 450-458.

Siegenthaler JA, Pleasure SJ. 2010. There's no place like home for a neural stem cell. Cell Stem Cell 7: 141-143.

Song J, Christian KM, Ming GL, Song H. 2012a. Modification of hippocampal circuitry by adult neurogenesis. $\mathrm{Dev}$ Neurobiol 72: 1032-1043.

Song J, Zhong C, Bonaguidi MA, Sun GJ, Hsu D, Gu Y, Meletis K, Huang ZJ, Ge S, Enikolopov G, et al. 2012b. Neuronal circuitry mechanism regulating adult quiescent neural stem-cell fate decision. Nature 489: 150-154.

Song J, Sun J, Moss J, Wen Z, Sun GJ, Hsu D, Zhong C, Davoudi H, Christian KM, Toni N, et al. 2013. Parvalbumin interneurons mediate neuronal circuitry-neurogenesis coupling in the adult hippocampus. Nat Neurosci 16: $1728-1730$.

Soumier A, Banasr M, Goff LK, Daszuta A. 2010. Regionand phase-dependent effects of $5-\mathrm{HT}_{1 \mathrm{~A}}$ and $5-\mathrm{HT}_{2 \mathrm{C}}$ receptor activation on adult neurogenesis. Eur Neuropsychopharmacol 20: 336-345.

Sun B, Halabisky B, Zhou Y, Palop JJ, Yu G, Mucke L, Gan L. 2009. Imbalance between GABAergic and glutamatergic transmission impairs adult neurogenesis in an animal model of Alzheimer's disease. Cell Stem Cell 5: 624-633.

Tashiro A, Zhao C, Gage FH. 2006. Retrovirus-mediated single-cell gene knockout technique in adult newborn neurons in vivo. Nat Protoc 1: 3049-3055.

Tecott LH, Maricq AV, Julius D. 1993. Nervous system distribution of the serotonin 5-HT3 receptor mRNA. Proc Natl Acad Sci 90: 1430-1434.

Teles-Grilo Ruivo LM, Mellor JR. 2013. Cholinergic modulation of hippocampal network function. Front Synaptic Neurosci 5: 2.

Temple S, Alvarez-Buylla A. 1999. Stem cells in the adult mammalian central nervous system. Curr Opin Neurobiol 9: $135-141$.

Toni N, Laplagne DA, Zhao C, Lombardi G, Ribak CE, Gage FH, Schinder AF. 2008. Neurons born in the adult dentate gyrus form functional synapses with target cells. Nat Neurosci 11: 901-907.

Tozuka Y, Fukuda S, Namba T, Seki T, Hisatsune T. 2005. GABAergic excitation promotes neuronal differentiation in adult hippocampal progenitor cells. Neuron 47: 803815.

Van der Borght K, Mulder J, Keijser JN, Eggen BJ, Luiten PG, Van der Zee EA. 2005. Input from the medial septum regulates adult hippocampal neurogenesis. Brain Res Bull 67: 117-125.

Van Kampen JM, Hagg T, Robertson HA. 2004. Induction of neurogenesis in the adult rat subventricular zone and neostriatum following dopamine D3 receptor stimulation. Eur J Neurosci 19: 2377-2387.

van Praag H, Schinder AF, Christie BR, Toni N, Palmer TD, Gage FH. 2002. Functional neurogenesis in the adult hippocampus. Nature 415: 1030-1034.

Vertes RP, Fortin WJ, Crane AM. 1999. Projections of the median raphe nucleus in the rat. J Comp Neurol 407: $555-582$.

Vilaro MT, Cortes R, Gerald C, Branchek TA, Palacios JM, Mengod G. 1996. Localization of 5-HT4 receptor 
mRNA in rat brain by in situ hybridization histochemistry. Brain Res Mol Brain Res 43: 356-360.

Vivar C, Potter MC, Choi J, Lee JY, Stringer TP, Callaway EM, Gage FH, Suh H, van Praag H. 2012. Monosynaptic inputs to new neurons in the dentate gyrus. Nat Commun 3: 1107.

Wang DD, Krueger DD, Bordey A. 2003. GABA depolarizes neuronal progenitors of the postnatal subventricular zone via $\mathrm{GABA}_{\mathrm{A}}$ receptor activation. J Physiol 550: 785-800.

Wang LP, Kempermann G, Kettenmann H. 2005. A subpopulation of precursor cells in the mouse dentate gyrus receives synaptic GABAergic input. Mol Cell Neurosci 29: 181-189.

Winner B, Geyer M, Couillard-Despres S, Aigner R, Bogdahn U, Aigner L, Kuhn G, Winkler J. 2006. Striatal deafferentation increases dopaminergic neurogenesis in the adult olfactory bulb. Exp Neurol 197: 113-121.
Neuronal Circuitry and Mammalian Neurogenesis

Witter MP. 2007. The perforant path: Projections from the entorhinal cortex to the dentate gyrus. Prog Brain Res 163: $43-61$.

Young SZ, Taylor MM, Bordey A. 2011. Neurotransmitters couple brain activity to subventricular zone neurogenesis. Eur J Neurosci 33: 1123-1132.

Zhao C, Teng EM, Summers RG Jr, Ming GL, Gage FH 2006. Distinct morphological stages of dentate granule neuron maturation in the adult mouse hippocampus. J Neurosci 26: 3-11.

Zhao C, Deng W, Gage FH. 2008. Mechanisms and functional implications of adult neurogenesis. Cell 132: 645660.

Zhou M, Li W, Huang S, Song J, Kim JY, Tian X, Kang E, Sano Y, Liu C, Balaji J, et al. 2013. mTOR Inhibition ameliorates cognitive and affective deficits caused by Discl knockdown in adult-born dentate granule neurons. Neuron 77: 647-654. 


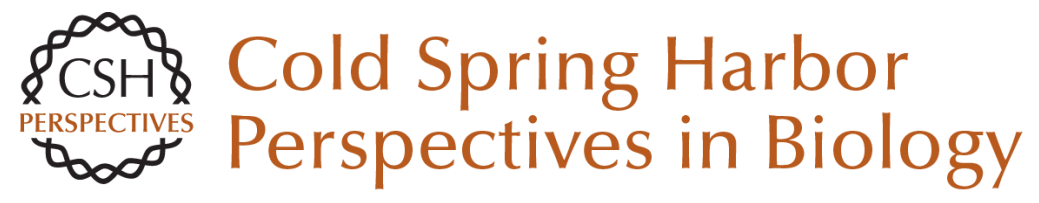

\section{Neuronal Circuitry Mechanisms Regulating Adult Mammalian Neurogenesis}

Juan Song, Reid H.J. Olsen, Jiaqi Sun, Guo-li Ming and Hongjun Song

Cold Spring Harb Perspect Biol 2016; doi: 10.1101/cshperspect.a018937 originally published online May 3, 2016

\section{Subject Collection Neurogenesis}

Adult Neurogenesis and Psychiatric Disorders Eunchai Kang, Zhexing Wen, Hongjun Song, et al.

Neuronal Circuitry Mechanisms Regulating Adult Mammalian Neurogenesis Juan Song, Reid H.J. Olsen, Jiaqi Sun, et al.

Neurogenesis in the Developing and Adult Brain --Similarities and Key Differences Magdalena Götz, Masato Nakafuku and David Petrik

Genetics and Epigenetics in Adult Neurogenesis Jenny Hsieh and Xinyu Zhao

The Adult Ventricular-Subventricular Zone (V-SVZ) and Olfactory Bulb (OB) Neurogenesis Daniel A. Lim and Arturo Alvarez-Buylla

Diversity of Neural Precursors in the Adult Mammalian Brain Michael A. Bonaguidi, Ryan P. Stadel, Daniel A. Berg, et al.

Detection and Phenotypic Characterization of Adult Neurogenesis

H. Georg Kuhn, Amelia J. Eisch, Kirsty Spalding, et al.

Maturation and Functional Integration of New Granule Cells into the Adult Hippocampus Nicolas Toni and Alejandro F. Schinder
Adult Olfactory Bulb Neurogenesis

Pierre-Marie Lledo and Matt Valley

Adult Neurogenesis in Fish Julia Ganz and Michael Brand

In Vitro Models for Neurogenesis Hassan Azari and Brent A. Reynolds Engineering of Adult Neurogenesis and
Gliogenesis

Benedikt Berninger and Sebastian Jessberger

Computational Modeling of Adult Neurogenesis James B. Aimone

Control of Adult Neurogenesis by Short-Range

Morphogenic-Signaling Molecules Youngshik Choe, Samuel J. Pleasure and Helena Mira

Adult Neurogenesis: An Evolutionary Perspective Gerd Kempermann

Epilepsy and Adult Neurogenesis

Sebastian Jessberger and Jack M. Parent

For additional articles in this collection, see http://cshperspectives.cshlp.org/cgi/collection/

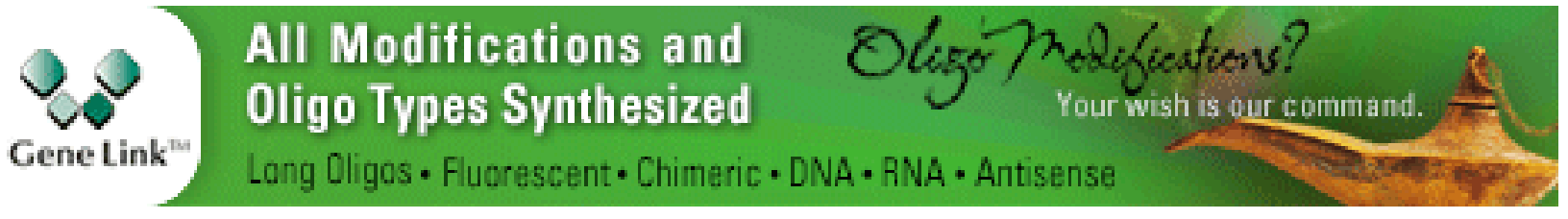


For additional articles in this collection, see http://cshperspectives.cshlp.org/cgi/collection/

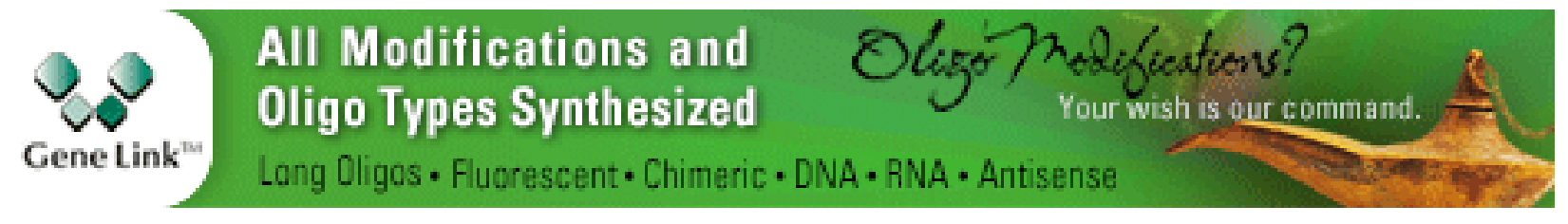

Copyright @ 2016 Cold Spring Harbor Laboratory Press; all rights reserved 